\title{
Article
}

\section{Neuropsychiatric outcomes of stroke}

\author{
Hackett, Maree L, Köhler, Sebastian, O'Brien, John T and Mead, \\ Gillian E
}

Available at http://clok.uclan.ac.uk/13648/

Hackett, Maree L ORCID: 0000-0003-1211-9087, Köhler, Sebastian, O'Brien, John T and Mead, Gillian E (2014) Neuropsychiatric outcomes of stroke. The Lancet Neurology, 13 (5). pp. 525-534. ISSN 14744422

It is advisable to refer to the publisher's version if you intend to cite from the work. http://dx.doi.org/10.1016/S1474-4422(14)70016-X

For more information about UCLan's research in this area go to http://www.uclan.ac.uk/researchgroups/ and search for < name of research Group>.

For information about Research generally at UCLan please go to http://www.uclan.ac.uk/research/

All outputs in CLoK are protected by Intellectual Property Rights law, including Copyright law. Copyright, IPR and Moral Rights for the works on this site are retained by the individual authors and/or other copyright owners. Terms and conditions for use of this material are defined in the policies page.

\section{CLoK}

Central Lancashire online Knowledge www.clok.uclan.ac.uk

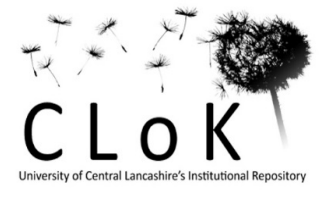




\section{Neuropsychiatric consequences of stroke: a review}

Maree L Hackett PhD

Sebastian Köhler PhD

John T O’Brien DM

Gillian E Mead FRCP
Associate Professor, Head of Mental Health and Chronic Disease program, The George Institute for Global Health, The University of Sydney. Reader in Epidemiology, School of Health, The University of Central Lancashire, Preston, United Kingdom

Research fellow, Alzheimer Centre Limburg, School for Mental Health and Neuroscience, Maastricht University, The Netherlands

Professor of Old Age Psychiatry, Department of Psychiatry, University of Cambridge and Cambridgeshire and Peterborough NHS Foundation Trust

Professor of Stroke and Elderly Care Medicine, Geriatric Medicine; Centre for Clinical Brain Sciences and Centre for Cognitive Ageing and Cognitive Epidemiology, University of Edinburgh

Key words

Stroke, Neuropsychiatric, depression, anxiety, emotional lability, fatigue, mania, psychosis, apathy

Word count 3997(excluding panel and search strategy) 
List of figures/ tables

1. Figure 1. Forest plot of treatments for post-stroke depression (permission from Maree Hackett and Cochrane Library)

2. Figure 2. Forest plot-pharmacological interventions for treating emotionalism after stroke (permission from Maree Hackett and Cochrane Library)

3. Table summarising longitudinal studies of post-stroke fatigue

\section{Panel 1}

Search strategy (see appendix)

\section{Panel 2}

\section{Areas for research}

Is there a common cause for neuropsychiatric consequences of stroke, which might explain the overlapping symptoms?

What factors are associated with anxiety, emotional lability and post stroke fatigue without mood disorder?

What is the natural course of post stroke anxiety and emotional lability?

How should post stroke depression, emotional lability, fatigue and apathy be treated (including dose and duration of treatment)?

Can these neuropsychiatric consequences of stroke be prevented by early intervention after stroke? 


\begin{abstract}
The most common neuropsychiatric consequences of stroke include depression, anxiety, fatigue and apathy, each occurring in at least $30 \%$ of patients, with considerable overlap of prevalence and symptoms. Emotional lability, personality change, psychosis and mania are less common but are equally distressing symptoms which are also challenging to manage. The cause of these syndromes is uncertain, and there is no clear relationship with brain lesion location. There are important gaps in our knowledge about how to manage them; even for depression which is the most well-studied syndrome. Further research is needed to identify causes, and interventions to prevent and treat these syndromes.
\end{abstract}




\section{Introduction}

Each year, about 16 million people in the world experience a first-ever stroke. Of these about 5.7 million die and another 5 million remain disabled. ${ }^{1}$ Neuropsychiatric consequences of stroke are common, can be distressing to patients and their families and often represent an unmet need for treatment. ${ }^{2}$

This review focuses on the most common non-cognitive neuropsychiatric consequences of stroke namely depression, anxiety, emotional lability and apathy; we also include fatigue (which is generally categorised as 'neuropsychiatric') and discuss personality change, psychosis and mania. For each consequence, we discuss definition and identification, prevalence, associations, natural history/outcome, prevention and treatment, based on our literature searches, then make recommendations for future research. Researchers have tended to consider each neuropsychiatric consequence separately, so we follow this same approach, acknowledging though that there is considerable overlap between the syndromes. We include intracerebral haemorrhage and ischaemic stroke. We did not specifically search for, or include papers focusing on transient ischaemic attacks or subarachnoid haemorrhage. We do not include dementia.

\section{Our approach to the literature}

We searched Medline using the terms 'stroke', and each neuropsychiatric problem in turn, to identify systematic reviews and primary research (box). These searches complemented previous searches we had performed, and so Medline was not necessarily searched from its inception. We scrutinised the Cochrane Stroke Group list of reviews and the Royal College of Physicians (RCP) Guidelines for stroke $(2012)^{3}$ for which extensive literature searches had been performed. We screened reference lists of reviews. Our management recommendations 
are based on data from randomised controlled trials (RCTs) or meta-analyses of RCTs but not from uncontrolled case series. In the absence of such data, we provide consensus recommendations.

\section{Depression}

The US Diagnostic and Statistical Manual of Mental Disorders, DSM-5' requires 'depressed mood' or 'anhedonia/loss of interest or pleasure' for at least two weeks, plus at least four other symptoms which are persistent and interfere with daily life ('significant weight loss/gain; insomnia or hypersomnia; psychomotor agitation or retardation; fatigue or loss of energy; worthlessness or inappropriate guilt; diminished concentration or indecisiveness').

In busy and resource-poor clinical settings, it is often appropriate to first use an intervieweradministered or self-completed depression case-finding or screening tool, validated for use in stroke $^{5}$ (e.g. the 9-item Patient Health Questionnaire ${ }^{6}$, The Center of Epidemiological StudiesDepression Scale ${ }^{7}$, Hospital Anxiety and Depression Scale (HADS), the Hamilton Depression Rating Scale and the Beck Depression Inventory ${ }^{8}$.

When diagnosing depression, consideration may be given to ensure somatic symptoms such as psychomotor retardation, fatigue, sleep and appetite disturbances are related to mood, and not to the physical symptoms of stroke. However, this is difficult to implement in practice and there is evidence that psychomotor retardation and fatigue are highly sensitive for depression after stroke. ${ }^{9}$ These symptoms are unpleasant and the clinical goal should be to reduce all unpleasant symptoms where possible. Equally important is the need to ensure that disturbances in behaviour, facial expression and verbal communication resulting from the stroke event do not mask symptoms of depression.

RCP guidelines ${ }^{3}$ recommend that all stroke patients are screened for mood disorders within 6 weeks. However, such screening is only worthwhile if followed by a fuller clinical diagnostic 
assessment and an agreed management plan. ${ }^{10}$ Observer rated screening tools (e.g. Stroke Aphasic Depression Questionnaire ${ }^{11}$ or The Depression Intensity Scale Circles ${ }^{12}$ ) can be used to identify mood disturbance in people with aphasia or other communication problems; however, as for other screening, clinical judgement is then needed to decide if the patient has depression and whether treatment is needed.

Depression occurs more frequently after stroke than in the general population. Data in two independent systematic reviews (43 cohorts, 20,293 people $^{13}$ and 51 cohorts including 25,207 people ${ }^{14} ; 21$ cohorts included in both reviews) indicate that between $29 \%^{13}$ and $33 \%{ }^{14}$ of stroke patients experience depression up to one year after stroke. Estimates from individual studies assessing major depression meeting DSM criteria varied across studies from $2 \%$ during admission ${ }^{15}$ in one cohort to $31 \%$ at three months in a different cohort. ${ }^{16}$ In the latter cohort, major depression meeting DSM criteria was assessed over three years. Estimates were $31 \%$ at three months, $16 \%$ at 1 year, $19 \%$ at 2 and $29 \%$ at three years after stroke (only 50 participants remained in the final cohort). ${ }^{16}$

Population based stroke registers with long-term follow-up ${ }^{17-19}$ demonstrate that depression after stroke is a chronic relapsing disorder. Of people with depression at the first assessment, between $13 \%^{18}$ and $52 \%^{19}$ still had depression at a year. Approximately $15 \%$ of those without depression at initial assessment developed depression during the first year. ${ }^{17,19}$

One systematic review of observational studies of depression after stroke (20 cohorts, $\mathrm{n}=17,934$ ) indicates that only physical disability, stroke severity and cognitive impairment consistently show a positive association with depression (note that most included studies excluded people with pre-stroke depression). ${ }^{20} \mathrm{~A}$ second independent review using different methods included 10 cohorts $(n=16,045)^{13}$ and identified pre-stroke depression as being associated with subsequent depression after stroke, in addition to disability, stroke severity, cognitive impairment. Variables not associated with depression include older age, being 
female, having diabetes, stroke subtype, level of education, living alone or previous stroke. ${ }^{20}$ Only one cohort was included in both reviews. Only a small proportion of the variation in depression was accounted for, though the included studies generally had sample sizes which were too small for multivariate analyses.

A Cochrane review of pharmacological or psychological interventions to prevent post-stroke depression identified 14 trials involving 1515 people ${ }^{21}$, and reported a small but significant effect for psychological interventions (of various types) (4 trials) but no evidence of effect of antidepressants (10 trials) (figure 1). Four small antidepressant trials ${ }^{22-25}$ (384 people) potentially meeting Cochrane criteria have been published since the 2008 update, three ${ }^{22,24,25}$ showed some evidence of benefit of antidepressants, though their inclusion in the Cochrane review is unlikely to significantly change overall estimates of effect.

A Cochrane review of pharmacological or psychological interventions to treat depression after stroke identified 16 trials recruiting 1655 people $^{26}$ (figure 1) and showed that antidepressants (13 trials) are minimally effective (no evidence of differences in efficacy between antidepressants) with an increase in gastrointestinal and central nervous system (e.g. confusion, sedation, tremor) side effects. This is in line with a systematic review of trials in the general population showing antidepressants are minimally effective for mild to moderate depression, ${ }^{27}$ but of substantial benefit for severe depression. The Cochrane review found no evidence of effectiveness for psychological therapies alone (4 trials) in treating depression after stroke. ${ }^{26}$ One small antidepressant treatment trial (150 people) possibly meeting review criteria was identified since this review and showed a small benefit of treatment. ${ }^{28}$

The United Kingdom Royal College of Physicians guidance is that support and advice is the first-line management for patients with mild or moderate symptoms of depression, and psychosocial interventions should be considered ${ }^{3}$. These guidelines also recommend increased social interaction, exercise and goal setting (though our searches found insufficient evidence 
to support or refute their effectiveness). ${ }^{3}$ The American ${ }^{29}$ and European ${ }^{30}$ guidelines recommend pharmaceutical treatment (Selective Serotonin Reuptake Inhibitors or heterocyclics) for patients with depression 29,30 The guidelines recommend that treatment should be monitored for effectiveness, and antidepressants (if used) continued for at least 6 months after initial recovery. The choice of antidepressants for individual antidepressants can be guided by side effect profile e.g. antidepressants with sedative properties may be appropriate in patients with disturbed sleep.

\section{Anxiety}

The DSM-5 ${ }^{4}$ describes several anxiety disorders. Anxiety symptoms that are 'out of proportion to the actual threat or danger the situation poses', must be present for six months to meet diagnostic criteria for a Generalised Anxiety Disorder, plus at least three of the following symptoms: feeling wound-up, tense or restless; fatigued; difficulty concentrating; irritability; significant muscle tension; difficulty sleeping. To our knowledge, the $\operatorname{HADS}^{8}$ is the only anxiety-specific case-finding tool validated for use in stroke research and clinical settings with published sensitivity and specificity data. ${ }^{31,32}$ If the HADS is used to screen for anxiety, then as with other screening tools clinical judgement is then needed to decide if the patient has clinically significant anxiety and whether treatment is needed.

A systematic review (39 cohorts including 4,706 people) indicated that $24 \%$ of stroke patients had anxiety symptoms as assessed by a rating scale, and $18 \%$ experienced an anxiety disorder, over the first five years after stroke. ${ }^{33}$ In this review, three cohort studies (856 people) reported anxiety in individual participants over time; the proportion with persistent anxiety ranged from $38 \%$ to $76 \%$.

Studies evaluating factors correlated with anxiety in more than five cohorts have been narratively (but not systematically) reviewed. ${ }^{33}$ Depression was positively correlated with 
anxiety in six of six cohorts and quality of life was negatively correlated with anxiety in four of five cohorts. No association was found with age, sex or brain lesion location. The factors associated with anxiety in people without depression after stroke are unknown.

There are no studies on anxiety prevention after stroke. A Cochrane review of interventions to treat anxiety after stroke identified two trials involving 175 people. ${ }^{34}$ Both trials included people with co-morbid anxiety and depression and neither was placebo-controlled. Antidepressants alone or with psychotherapy may reduce anxiety symptoms but there is insufficient evidence from the Cochrane review to inform clinical practice.

\section{Emotional lability}

Emotional lability is described as 'unstable emotional experiences and frequent mood changes; emotions that are easily aroused, intense and/or out of proportion to events and circumstances'. ${ }^{4}$ It is also referred to as emotionalism, pathological laughing/crying, emotional incontinence, involuntary emotional expression disorder and pseudobulbar affect. There is no standard method of assessment. It usually presents as an increase in crying or, less commonly, laughing, and may co-exist with depression or depressive symptoms but can occur without depression. Symptoms are generally mild and transient, but when severe can cause great distress, embarrassment and avoidance of social contact.

A few high quality studies reported that the frequency of emotional lability ${ }^{35-41}$ varies across individual studies from $8 \%^{35}$ at four months in one cohort to $32 \%{ }^{37}$ three to 12 months after stroke in another. Symptoms are thought to reduce over the six months following stroke. ${ }^{36}$. The factors associated with reduction of symptoms are unknown.

There are no published systematic reviews of the associations of emotional lability after stroke. Most research has focused on biological explanations with an association between emotional 
lability and frontal lesions found in four cohorts ${ }^{36,41-43}$ and an association with dorsal lesions in the other. ${ }^{44}$

A Cochrane review of pharmacological interventions to treat emotional lability after stroke (seven trials, 739 people, recruited at 6 days to 13 years after stroke) reported that antidepressants reduced its frequency and severity but confidence intervals were wide (figure 2) ${ }^{45}$ It is reasonable to use antidepressants for persistent emotional lability that is frequent and severe enough to warrant the known risks of antidepressants ${ }^{3}$; but the optimum type, duration or dose is unknown.

\section{Post-stroke Fatigue}

There is no standardised definition for post-stroke fatigue. ${ }^{46}$ Physiological (or normal) fatigue (a state of general tiredness which develops acutely after overexertion and improves after rest) and pathological fatigue ('constant weariness unrelated to previous exertion levels and not usually ameliorated by rest'). ${ }^{47}$ tend to be distinguished in the literature, and in neurological diseases, 'pathological fatigue' is more prominent than 'physiological' fatigue. ${ }^{48}$ Post-stroke fatigue can be identified using a self-report fatigue scale, ${ }^{46}$ or by structured interview to establish fulfilment of a case definition (analogous to a structured interview to identify depression). ${ }^{47}$ There is little empirical evidence to support the concepts of 'Primary', 'secondary', 'central' and 'peripheral' fatigue in stroke . The proportion of people with poststroke fatigue ranges from $23 \%$ to $75 \%$, according to case mix, and how fatigue is identified.

${ }^{46}$ Using a case definition, about $40 \%$ of stroke patients have fatigue. ${ }^{49}$

A systematic review of 9 longitudinal cohort studies $(n=959)$ reported that the frequency of fatigue declined over time in seven studies $(n=764)$ and increased in two studies $(n=195) .{ }^{50}$ Two subsequent studies reported that fatigue frequency was stable over time. ${ }^{51}{ }^{52}$ (table) Fatigue tends to persist in individual patients if present early after stroke. ${ }^{50}$ 
The nature of post-stroke fatigue is different from fatigue experienced before stroke ${ }^{53}$ and it seems to start around the time of the stroke. ${ }^{54}$ There is no clear association with brain lesion location $^{55}$, little evidence about biological correlates. ${ }^{55}$ and one study demonstrating associations with attentional deficits. ${ }^{51}$ A literature review in 2011 reported associations with depression, pain and poor sleep. ${ }^{46}$ Fatigue in conditions other than stroke is associated with reduced physical activity; whether this applies in stroke is uncertain. ${ }^{56}$

A Cochrane review of 3 small randomised trials (142 people) which included fatigue as an outcome measure found no effective preventative or treatment strategies.${ }^{57}$ One subsequent trial $(n=83)$ without a control arm showed that treadmill aerobic training and cognitive behavioural therapy (CBT) together was better than CBT alone to treat post-stroke fatigue, ${ }^{58} \mathrm{~A}$ small trial $(n=19)$ demonstrated that group education was a feasible treatment. ${ }^{59}$ Screening for fatigue is not currently recommended in guidelines. In patients with post-stroke fatigue, we suggest seeking potentially reversible causes e.g. anaemia, treating depression (if present), and in patients without patients without a clinical mood disorder or reversible medical problem, considering graduated exercise and cognitive behavioural approaches e.g. activity scheduling 3 .

\section{Apathy}

Apathy is a disorder of motivation with diminished goal-directed behaviour and cognition ${ }^{60}$ which has its own distinct biological correlates, clinical course and treatment. Nevertheless phenomenological overlap (e.g. affective blunting, loss of interest, psychomotor retardation) with depression can make differential diagnosis difficult. ${ }^{60}$ Apathy can be identified by informant-rated scales e.g. Apathy Scale ${ }^{61}$ or Apathy Evaluation Scale ${ }^{62}$ ( designed and tested for use in brain-injured populations) or the generic Neuropsychiatric Inventory (NPI), also requiring an informant, which rates frequency and severity of several neuropsychiatric 
symptoms (delusions, hallucinations, agitation, depression, anxiety, mood elation, apathy, disinhibition, irritability, aberrant motor behaviour, sleep, appetite). ${ }^{63}$ Diagnostic criteria for apathy have recently been proposed, ${ }^{64}$ requiring diminished motivation (core feature) for four weeks or more, two other symptoms (reduced goal-directed behavior, goal-directed cognitive activity, or emotions), and functional impairments. Symptoms and states that mimic apathy should be excluded. These criteria largely build on studies in apathy in dementia; whether they are appropriate for stroke is uncertain.

In a meta-analysis of 2,706 patients from 24 studies, the mean prevalence of apathy was $34.6 \%$ at a median of 120 days post stroke. ${ }^{65}$ Another meta-analysis found similar figures. ${ }^{66}$ Apathy is more common in women, ${ }^{65}$ in studies using clinician-ratings compared to self-ratings or informant-ratings, ${ }^{65}$ and in recurrent strokes. ${ }^{66}$

We identified three prospective studies (recruiting 408, 106 and 145 stroke patients), but methodological differences make direct comparisons difficult. The proportion whose apathy had remitted at follow-up ranged from $44 \%{ }^{67}$ to $67 \%{ }^{68}$. The development of new apathy during follow-up occurred in only $7 \%$ of patients ${ }^{69}$.

In cross-sectional studies, apathy is associated with less education, cognitive impairment (particularly attention, concentration, working memory and reasoning) ${ }^{70}$ and increasing disability. ${ }^{65,}{ }^{66}$ Depression co-occurs in about $40 \%$ of apathetic patients. ${ }^{65}$ No convincing evidence links brain lesion location or stroke type to post-stroke apathy. ${ }^{65}$ We identified one publication that studied risk factors for apathy prospectively;, new incident apathy 15 months after stroke was predicted by a diagnosis of dementia three to six months after stroke, but not by age, gender, stroke severity, previous psychiatric history, current depressive symptoms, or living with a family member. ${ }^{67}$ Apathy is associated with worse functional outcome, ${ }^{71-73}$ and a higher risk of subsequent depression. ${ }^{67}$ 
There is insufficient evidence for treatment recommendations for post-stroke apathy. One RCT in 137 stroke patients with depression showed that $900 \mathrm{mg}$ /day nefiracetam for $\geq 4$ weeks resulted in a greater change in scores of the Apathy Scale (secondary outcome) compared to $600 \mathrm{mg}$ and placebo. ${ }^{74}$

\section{Mania}

Mania is defined as a prominent and persistently elevated, expansive or irritable mood, accompanied by changes in energy or activity, not accounted for by another mental disorders and not exclusively present in the course of delirium. ${ }^{4}$ Accompanying symptoms include hyperactivity, pressured speed, flight of ideas, grandiosity, decreased sleep, distractibility, or lack of judgement. Symptoms have to cause significant distress or impairment in social, occupation or other important functions. The clinical profile in post-stroke mania is similar to that of primary mania. ${ }^{75,76}$ We identified three scales for rating the severity of manic symptoms ${ }^{35-37}$ but no studies that have actually used these scales with stroke patients.

The literature on mania after stroke is meagre. Its prevalence is considered to be low $(\leq 2 \%)$, yet good epidemiological data are lacking. ${ }^{70}$ A systematic review of all studies published in the past 50 years identified 32 reports including only 49 patients, mostly gathered from single case or small case series reports. ${ }^{76}$ Delirium as a potential cause was specified in only about half of patients and a medical doctor or psychologist had conducted the interview in a minority (22\%). Onset in these 49 patients was generally reported to be insidious; about half develop manic symptoms within the first days after stroke and the rest 1 to 24 months after stroke. ${ }^{76}$ The prevalence of single manic symptoms has been reported for euphoria/elated mood using the NPI; prevalence estimates range from $1 \%$ to $14 \% .^{68,77-79}$

Our literature search identified no prospective studies on the course of mania after stroke, no studies reporting associations (other than the review of 49 individual cases which described the 
typical patient as being male, having vascular risk factors and a lesion in the right hemisphere) and no trials of interventions for prevention or treatment. No conclusive associations have been found with single symptoms of euphoria/elated mood.

\section{Personality disorders after stroke}

The DSM-V differentiates three clusters of Personality disorders ${ }^{4}$ In order to classify as personality disorder, the changes have to be long-standing and hence require long follow-up of individual patients. We are not aware of any such study in stroke. A cross-sectional survey in the UK reported personality disorders in $0.8 \%$ of individuals with stroke compared to $0.4 \%$ without stroke; it is unclear whether personality disorder might have preceded the stroke. ${ }^{80}$

\section{Personality changes, including disinhibition and irritability}

Personality changes after stroke are not well defined and at times are used as an umbrella term for any neuropsychiatric syndrome, especially apathy. ${ }^{70}$ Assessing change in personality can be challenging, because information on pre-stroke personality might not be available. The NPI asks informants to consider only changes in a patient's behaviour since illness onset. It includes questions on disinhibition and irritability, which are often classified as personality changes, ${ }^{81}$ and are among the most distressing symptoms for carers and family members. ${ }^{82,83}$ Irritability is characterized by impatience, flashes of anger, rapid mood changes, or quarreling ${ }^{79}$ and disinhibition by impulsivity, tactlessness or - albeit less often - by vulgarity. ${ }^{79}$

Prevalence estimates for irritability vary from $12-53 \% .{ }^{68,77}$ In a study of 274 institutionalized stroke patients, it was the more common (prevalence 52.9\%) than depressive symptoms $(52.6 \%)$ or apathy $(34.3 \%) .{ }^{77}$ It is more common in those with accompanying depression, ${ }^{84}$ emotional lability, ${ }^{85}$ and cognitive impairment. ${ }^{86}$ Prevalence estimates for disinhibition vary 
from $6-76 \%,{ }^{78,87}$ partly due to differences in scales used and research setting (e.g. higher prevalence in acute hospital, ${ }^{87}$ than rehabilitation center ${ }^{68}$ ).

Two studies of 11 and 49 affected patients respectively ${ }^{68,88}$ suggested that irritability tends to improve over time, and in one (n affected $=10)$ disinhibition improved over time. ${ }^{68}$

Our searches identified several studies reporting associations with brain lesion location; there is no consistent association with disinhibition, irritability, or aggression ${ }^{77}, 84,87,89-92$. Irritability/aggression has been associated with higher overall psychopathology, depression and anxiety, and poor cognition. ${ }^{91}$

Our searches identified no clinical trials on the prevention or treatment of personality changes, disinhibition or irritability after stroke. In a post-hoc analysis of a double-blind randomized controlled trial for treatment of post-stroke depression, antidepressant treatment significantly reduced irritability symptoms..$^{91}$

\section{Psychosis and psychotic symptoms}

'Psychosis' refers to disorders involving a severe distortion in thought content. While it is commonly used for schizophrenia and related disorders, it also applies to mania and severe depression. ${ }^{93}$ Single psychotic symptoms can also be due to other causes including delirium, dementia, or use of psychoactive drugs/dopamine agonists. The most prominent symptoms include delusions and hallucinations. Delusions are "erroneous beliefs that usually involve the misinterpretation of perceptions and experiences". ${ }^{93}$ Hallucinations are abnormal perceptions that are not experienced by others, which can occur in any modality and can be simple (e.g. light flashes, single sounds) or complex (e.g. seeing whole scenes, hearing voices, seeing objects in Lilliputian form (i.e. smaller than normal). ${ }^{56}$ Most research in stroke populations has 
used the NPI, which includes two sections on the frequency and severity of any-type of delusions and hallucinations ${ }^{63}$ rather than specific scales e.g. Positive and Negative Symptom Scale ${ }^{94}$ and the Brief Psychotic Rating Scale. ${ }^{95}$ There is no literature about which is the most appropriate scale to use in stroke.

Our literature search did not identify any high-quality epidemiological studies with active case ascertainment. Two hospital-registry studies identified only $0.4 \%{ }^{96}$ and $3.1 \%{ }^{97}$ of stroke patients with a psychotic disorder. The incidence was 1.11 per 1000 person-years, with gradual onset at an average of 6.1 months after stroke. ${ }^{97}$ Single psychotic symptoms not fulfilling criteria for syndromal psychotic disorder appear more common. For example, among patients admitted to somatic or rehabilitation wards of Dutch nursing homes, delusional symptoms were present in $3-10 \%$ of patients ${ }^{68,77}$ and hallucinations in about $4 \% .68,77$ Visual hallucinations are more common (12\%) in patients with occipital strokes. ${ }^{98}$ Auditory hallucinations were present in 4 out of $521(0.8 \%)$ patients with cortical stroke, ${ }^{99}$ though they might be more common in subcortical strokes. ${ }^{100}$ Note that we cannot rule out the possibility that some of these patients may have had delirium as a cause of psychotic symptoms. There is insufficient information on lesion location or the outcome of psychosis and psychotic symptoms. In a retrospective cohort study of 1008 stroke patients, psychosis was the only neuropsychiatric disorder significantly associated with a higher mortality rate, but why this should be specific to psychosis is obscure. ${ }^{97}$ No prospective studies on the course and outcome of post-stroke psychosis are available. No clinical trial reported on prevention or treatment of psychosis after stroke.

Research directionsThere is considerable overlap between each neuropsychiatric syndrome.. Depression frequently coexists with anxiety and emotional lability, fatigue is a symptom of depression and anxiety, apathy is associated with depression and cognitive impairment, and personality changes are associated with emotional lability, depression and 
cognitive impairment. This raises the question about whether there are shared underlying mechanisms e.g. fluctuations in neurotransmitters, aspects of the inflammatory cascade, disrupted functional connectivity in the limbic system and inability to regulate arousal. Brain lesion location seems not to be associated with specific syndromes (except for visual hallucinations)

. There was a dearth of literature on apathy, even though it is reported to be as common as depression.

There are important knowledge gaps in relation to management. Even for depression there is no clear evidence about how to treat patients with mild to moderate post-stroke depression, and a dearth of evidence about how to manage people with suspected depression in whom mood cannot be formally assessed because of aphasia.

Further studies exploring the associations and outcome of these syndromes (particularly emotional lability, personality change, apathy and psychosis) are needed to identify associated factors that might be potential targets for prevention and treatment. Robustly designed prevention and treatment trials are needed for each of the syndromes, perhaps by adapting for interventions that have been used in other conditions The trials we identified were generally small. Large, high-quality, well-powered trials are needed that will provide definitive answers about the effectiveness (or not) of interventions. 
Conflict of interest. Prof Mead has received expenses to lecture on post-stroke fatigue at international meetings, honoraria to produce a module on exercise after stroke for the World Stroke Organisation, and royalties from Later Life Training, for provide teaching material on exercise after stroke. A/Prof Hackett has received expenses to lecture on post-stroke depression at international meetings. John O'Brien has received travel support and/or honoraria for non-promotional lectures from Pfizer, Eisai, Lundbeck, Novartis, Lilly and Shire and acted as a consultant for GE Healthcare, Bayer Healthcare, Lilly, TauRx and Cytox. Sebastian Köhler reports no conflicts of interest.

\section{Role of the authors}

Maree Hackett performed the literature searches for the sections on depression, anxiety and emotional lability, and wrote these sections. Professor Mead performed the literature searches for fatigue. Sebastian Köhler performed the literature searches for the sections on apathy, mania, personality changes and psychosis and wrote the first draft of these sections. John O'Brien provided additional references. All authors commented on drafts of the paper, and all contributed equally to the final section on directions for future research. Permissions for the figures were obtained by Maree Hackett and Gillian Mead. 


\section{Table}

Summary of longitudinal studies of post-stroke fatigue, adapted from Journal of Psychosomatic Research

\begin{tabular}{|c|c|c|c|c|}
\hline Study & $\begin{array}{l}\text { Assessment } \\
\text { points }\end{array}$ & $\begin{array}{l}\text { Sample size } \\
\text { reported at } \\
\text { first time point }\end{array}$ & $\begin{array}{l}\text { Frequency of } \\
\text { fatigue at first } \\
\text { time point }\end{array}$ & $\begin{array}{c}\text { Frequency of } \\
\text { fatigue at } \\
\text { last time } \\
\text { point }\end{array}$ \\
\hline Schepers 2006 & $\mathrm{~A}, 6 \mathrm{~m}, 12 \mathrm{~m}$ & 167 & $52 \%$ & $70 \%$ \\
\hline $\begin{array}{l}\text { Van der Port } \\
2007\end{array}$ & $6 \mathrm{~m}, 12 \mathrm{~m}, 36 \mathrm{~m}$ & 223 & $68 \%$ & $58 \%$ \\
\hline Skaner 2007 & $3 \mathrm{~m}, 12 \mathrm{~m}$ & 106 & $69 \%$ & $58 \%$ \\
\hline Sisson 1995 & $1 \mathrm{~m}, 6 \mathrm{~m}$ & 13 & $92 \%$ & $85 \%$ \\
\hline $\begin{array}{l}\text { Christensen } \\
2008\end{array}$ & $\begin{array}{l}10 d, 3 m, 12 m, 24 \\
m\end{array}$ & 138 & $59 \%$ & $40 \%$ \\
\hline Snaphaan 2011 & $2 \mathrm{~m}, 18 \mathrm{~m}$ & 108 & $35 \%$ & $33 \%$ \\
\hline $\begin{array}{l}\text { Hellawell } 1999 \\
\text { (subarachnoid } \\
\text { haemorrhage } \\
\text { people) }\end{array}$ & $6 \mathrm{~m}, 12 \mathrm{~m}, 24 \mathrm{~m}$ & 28 & $65 \%$ & $68 \%$ \\
\hline Ogden 1994 & $10 w, 12 m$ & 89 & $89 \%$ & $86 \%$ \\
\hline Noble 2008 & $\begin{array}{l}24-251 d, 335- \\
672 d\end{array}$ & 73 & $59 \%$ & $36 \%$ \\
\hline $\begin{array}{l}\text { Van Eijsden } \\
2012\end{array}$ & $D, 24 w$ & 242 & $58 \%$ & $55 \%$ \\
\hline Radman 2012 & $6 \mathrm{~m}, 12 \mathrm{~m}$ & 109 & $33 \%$ & $34 \%$ \\
\hline
\end{tabular}

Abbreviations: $A=$ admission; $d=$ days; $D=$ discharge; $m=$ months; $w=$ weeks 


\section{Box 1}

\section{Search strategies}

\section{Depression search strategy}

Medline searched till 19/06/2013 (from date based on last published systematic review)

Stroke AND Depression (2004- )

- depressive disorder/ or depressive disorder, major/ or depressive disorder, treatmentresistant/ or dysthymic disorder/ or depression/ or exp antidepressive agents/

- (depress \$ or dysthymi\$ or dysphor\$ or antidepress\$ or anti-depress\$).tw

Anxiety search strategy

Medline (2011- )

- anxiety/

- exp anxiety disorder/

- exp anxiolytic agent/

- (anxiety or anxieties or anxious or agoraphobi\$ or phobi\$ or panic disorder\$ or panic attack\$ or (obsess \$ adj3 compuls\$) or post?traumatic stress\$ or PTSD).tw.

- (feel\$ adj5 (apprehens $\$$ or dread or disaster\$ or fear\$ or worry or worried or terror)).tw

- anxiety inventory.mp.

- anxiety scale.mp.

\section{Emotional lability search strategy}

Medline (2008- )

- crying/ or laughter/

- affective symptoms/ or emotions/

- (laugh\$ or cry\$ or weep or weeping or emotional\$ or pseudobulbar affect).tw.

\section{Fatigue}

Medline July 2013 all indexed articles, no start date

Fatigue AND stroke (to complement more extensive searches performed for published systematic reviews in 2012-See Duncan et al 2012)

Apathy, mania, psychosis, personality changes

Medline search on 15 JULY 2013; all indexed articles, no start date; 
Filters: Humans, English language

Stroke AND

(apathy OR apathetic).af

(mania OR manic OR bipolar OR).af

(psychosis OR psychotic OR delusions OR hallucinations).af

AND personality.af

AND (irritability or irritable).af

AND (disinhibit* or impulsiv*).af

In September 2013, an additional search was done for euphoria.

stroke AND (euphoria OR euphoric OR hypomania)).af 


\section{References}

1. Strong K, Mathers C, Bonita R. Preventing stroke: saving lives around the world. Lancet Neurology 2007; 6: 182-7.

2. McKevitt C, Fudge N, Redfern J, et al. Self-Reported Long-Term Needs After Stroke. Stroke 2011; 42: 1398-403.

3. Intercollegiate Stroke Working Party. National clinical guideline for stroke, 4th edition. London: Royal College of Physicians; 2012.

4. American Psychiatric Association. Diagnostic and Statistical Manual of Mental Disorders (Fifth ed.). Fifth ed. Arlington, VA: American Psychiatric Publishing.; 2013.

5. Meader N, Moe-Byrne T, Llewellyn A, Mitchell AJ. Screening for poststroke major depression: a meta-analysis of diagnostic validity studies. Journal of Neurology Neurosurgy and Psychiatry 2013; Published Online First: 5 Feb 2013; doi:10.1136/jnnp-2012-304194.

6. Kroenke K, Spitzer R, Williams J. The PHQ-9: validity of a brief depression severity measure. J Gen Intern Med 2001; 16(9): 606-13.

7. Radloff LS. The CES-D scale: a self report depression scale for research in the general population. Applied Psychological Measurement 1977; 1: 385-401.

8. Zigmond AS, Snaith RP. The Hospital Anxiety and Depression Scale. Acta Psychiatrica Scandinavica 1983; 67: 361-70.

9. Coster LD LA, Lodder J, Verhey FRJ. The sensitivity of somatic symptoms in poststroke depression: a discriminant analytic approach. Int J Geriat Psychiatry 2005; 20: 358-62. 10. Gilbody S, Sheldon T, House A. Screening and case-finding instruments for depression: a meta-analysis. Canadian Medical Association Journal 2008; 178(8): 997-1003.

11. Benaim C, Cailly B, Perennou D, Pelissier J. Validation of the Aphasic Depression Rating Scale. Stroke 2004; 35: 1692-6. 
12. Turner-Stokes L, Kalmus M, Hirani D, Clegg F. The Depression Intensity Scale Circles (DISCs): a first evaluation of a simple assessment tool for depression in the context of brain injury. Journal of Neurology, Neurosurgery \& Psychiatry 2005; 76: 1273-8.

13. Ayerbe L, Ayis S, Wolfe CDA, Rudd AG. Natural history, predictors and outcomes of depression after stroke: systematic review and meta-analysis The British Journal of Psychiatry 2012; 202: 14-21.

14. Hackett ML, Yapa C, Parag V, Anderson CS. The frequency of depression after stroke: a systematic review of observational studies. Stroke 2005; 36: 1330-40.

15. Loong CK, Kenneth NKC, Paulin ST. Post-stroke depression: Outcome following rehabilitation. Aust N Z J Psych 1995; 29(4): 609-14.

16. Åström M, Adolfsson R, Asplund K. Major depression in stroke patients: a 3-year longitudinal study. Stroke 1993; 24: 976-82.

17. Ayerbe L, Ayis S, Crichton SL, Wolfe CDA, Rudd AG. The natural history of depression up to 15 years after stroke: The South London Stroke Register. Stroke 2013; Published online before print February 12, 2013, doi: 10.1161/ STROKEAHA.111.679340.

18. House A, Dennis M, Warlow C, Hawton K, Molyneux A. Mood disorders after stroke and their relation to lesion location: a CT scan study. Brain 1990; 113: 1113-29.

19. Wade DT, Legh-Smith J, Hewer RA. Depressed mood after stroke. A community study of its frequency. British Journal of Psychiatry 1987; 151: 200-5.

20. Hackett ML, Anderson CS. Predictors of depression after stroke: a systematic review of observational studies. Stroke 2005; 36: 2296-301.

21. Hackett ML, Anderson CS, House AO, Halteh C. Interventions for preventing depression after stroke. Cochrane Database of Systematic Reviews 2008; Issue 1: Art. No.: CD003689. DOI: 10.1002/14651858.CD003689.pub3. 
22. Chollet F, Tardy J, Albucher J-F, et al. Fluoxetine for motor recovery after acute ischaemic stroke (FLAME): a randomised placebo-controlled trial.[Erratum appears in Lancet Neurol. 2011 Mar;10(3):205]. Lancet Neurology 2011; 10(2): 123-30.

23. Robinson RG, Jorge RE, Moser DJ, et al. Escitalopram and problem-solving therapy for prevention of poststroke depression: a randomized controlled trial.[Erratum appears in JAMA. 2009 Mar 11;301(10):1024]. JAMA 2008; 299(20): 2391-400.

24. Tsai C-S, Wu C-L, Chou S-Y, Tsang H-Y, Hung T-H, Su J-A. Prevention of poststroke depression with milnacipran in patients with acute ischemic stroke: a double-blind randomized placebo-controlled trial. International Clinical Psychopharmacology 2011; 26(5): 263-7.

25. $\mathrm{Xu} \mathrm{J,} \mathrm{Wang} \mathrm{J,} \mathrm{Liu} \mathrm{J.} \mathrm{Preventive} \mathrm{effects} \mathrm{of} \mathrm{antidepressants} \mathrm{on} \mathrm{post-stroke} \mathrm{depression.}$ Chinese Mental Health Journal 2006; 20(3): 186-8.

26. Hackett ML, Anderson CS, House AO, Xia J. Interventions for treating depression after stroke. Cochrane Database of Systematic Reviews 2008; Issue 2: Art. No.: CD003437. DOI: 10.1002/14651858.CD003437.pub3.

27. Fournier JC, De Rubeis RJ, Hollon SD, et al. Antidepressant drug effects and depression severity: a patient-level meta-analysis. JAMA 2010; 303: 47-53.

28. Li L-T, Wang S-H, Ge H-Y, Chen J, Yue S-W, Yu M. The beneficial effects of the herbal medicine Free and Easy Wanderer Plus (FEWP) and fluoxetine on post-stroke depression. Journal of Alternative \& Complementary Medicine 2008; 14(7): 841-6.

29. Miller EM ML, Richards L, Zorowitz RD, Bakas T, Clark P, Billinger SA. Comprehensive Overview of Nursing and Interdisciplinary Rehabilitation Care of the Stroke Patient: A Scientific Statement From the American Heart Association. . Stroke 2010; 41: 240248.

30. Quinn TJ PS, Sunnerhagen KS, Sivenius J, Walker MF, Toni D, Lees KR. Evidencebased stroke rehabilitation: an expanded guidance document from the European Stroke 
Organisation (ESO) guidelines for management of ischaemic stroke and transient ischaemic attack 2008. J Rehabil Med 2009; 41(2): 99-111.

31. Johnson G, Burvill PW, Anderson CS, Jamrozik K, Stewart-Wynne EG, Chakera TM. Screening instruments for depression and anxiety following stroke: experience in the Perth community stroke study. Acta Psychiatrica Scandinavica 1995; 91: 252-7.

32. Sagen U, Vik TG, Moum T, Mørland T, Finset A, Dammen T. Screening for anxiety and depression after stroke: Comparison of the Hospital Anxiety and Depression Scale and the Montgomery and Åsberg Depression Rating Scale Journal of Psychosomatic Research 2009; 67(4): $325-32$.

33. Campbell Burton CA MJ, Holmes J, Astin F, Greenwood D, Knapp P. Frequency of anxiety after stroke: a systematic review and meta-analysis of observational studies. International Journal of Stroke 2012; Sep 27. doi: 10.1111/j.1747-4949.2012.00906.x.

34. Campbell Burton CA, Holmes J, Murray J, et al. Interventions for treating anxiety after stroke. Cochrane Database of Systematic Reviews 2011; 2011(12): Art. No.: CD008860.

35. Burvill PW, Johnson GA, Jamrozik KD, Anderson CS, Stewart-Wynne EG, Chakera TM. Anxiety disorders after stroke: results from the Perth Community Stroke Study. British Journal of Psychiatry 1995; 166: 328-32.

36. House A, Dennis M, Molyneux A, Warlow C, Hawton K. Emotionalism after stroke. BMJ 1989; 298: 991-4.

37. Kim JS, Choi S, Kwon SU, Seo YS. Inability to control anger or aggression after stroke. Neurology 2002; 58: 1106-8.

38. Morris PLP, Robinson RG, Raphael B. Prevalence and Course of Depressive-Disorders in Hospitalized Stroke Patients. International Journal of Psychiatry in Medicine 1990; 20(4): 349-64. 
39. Tang WK, Chan SSM, Chiu HFK, et al. Emotional incontinence in Chinese stroke patients: diagnosis, frequency and clinical and radiological correlates. Journal of Neurology 2004; 251: 865-9.

40. Tang WK, Chen YK, Lam WWM, et al. Emotional incontinence and executive function in ischemic stroke: A case-controlled study. Journal of the International Neuropsychological Society 2009; 15: 62-8.

41. Tang WK, Chen YK, Lu JY, et al. Microbleeds and post-stroke emotional lability. Journal of Neurology Neurosurgery \& Psychiatry 2009; 80: 1082-6.

42. Kim JS, Choi-Kwon S. Poststroke depression and emotional incontinence: correlation with lesion location. Neurology 2000; 54(9): 1805-10.

43. Morris PLP, Robinson RG, Raphael B. Emotional lability after stroke. Aust N Z J Psych 1993; 27(4): 601-5.

44. Kim JS. Post-stroke emotional incontinence after small lenticulocapsular stroke: Correlation with lesion location. Journal of Neurology 2002; 249(7): 805-10.

45. Hackett ML, Yang M, Anderson CS, Horrocks JA, House A. Pharmaceutical interventions for emotionalism after stroke. Cochrane Database of Systematic Reviews 2010; Issue 2. Art. No.: CD003690. DOI: 10.1002/14651858.CD003690.pub3.

46. Choi-Kwon S, Han SW, Kwon SU, Kim JS. Poststroke fatigue: characteristics and related factors. Cerebrovasc Dis 2005; 19(2): 84-90.

47. De Groot MH, Phillips SJ, Eskes GA. Fatigue associated with stroke and other neurologic conditions: Implications for stroke rehabilitation. Arch Phys Med Rehabil 2003; 84(11): 1714-20.

48. Chaudhuri A, Behan PO. Fatigue in neurological disorders. Lancet 2004; 363(9413): 978-88. 
49. Lynch J, Mead G, Greig C, Young A, Lewis S, Sharpe M. Fatigue after stroke: the development and evaluation of a case definition. J Psychosom Res 2007; 63(5): 539-44.

50. Duncan F, Wu S, Mead GE. Frequency and natural history of fatigue after stroke: a systematic review of longitudinal studies. J Psychosom Res 2012; 73(1): 18-27.

51. Radman N, Staub F, Aboulafia-Brakha T, Berney A, Bogousslavsky J, Annoni JM. Poststroke fatigue following minor infarcts: a prospective study. Neurology 2012; 79(14): $1422-7$.

52. Lerdal A, Lee KA, Bakken LN, Finset A, Kim HS. The Course of Fatigue during the First 18 Months after First-Ever Stroke: A Longitudinal Study. Stroke Res Treat 2012; 2012: 126275.

53. Flinn NA, Stube JE. Post-stroke fatigue: qualitative study of three focus groups. Occup Ther Int 2010; 17(2): 81-91.

54. McKechnie F, Lewis S, Mead G. A pilot observational study of the association between fatigue after stroke and C-reactive protein. J R Coll Physicians Edinb 2010; 40(1): 9-12.

55. Kutlubaev MA, Duncan FH, Mead GE. Biological correlates of post-stroke fatigue: a systematic review. Acta Neurol Scand 2012; 125(4): 219-27.

56. Duncan F, Kutlubaev MA, Dennis MS, Greig C, Mead GE. Fatigue after stroke: a systematic review of associations with impaired physical fitness. Int J Stroke 2012; 7(2): 157 62.

57. McGeough E, Pollock A, Smith LN, et al. Interventions for post-stroke fatigue. Cochrane Database Syst Rev 2009; (3): CD007030.

58. Zedlitz AM, Rietveld TC, Geurts AC, Fasotti L. Cognitive and graded activity training can alleviate persistent fatigue after stroke: a randomized, controlled trial. Stroke 2012; 43(4): 1046-51. 
59. Clarke A, Barker-Collo SL, Feigin VL. Poststroke fatigue: does group education make a difference? A randomized pilot trial. Top Stroke Rehabil 2012; 19(1): 32-9.

60. Starkstein SE, Leentjens AF. The nosological position of apathy in clinical practice. Journal of Neurology, Neurosurgery, and Psychiatry 2008; 79(10): 1088-92.

61. Starkstein SE, Mayberg HS, Preziosi TJ, Andrezejewski P, Leiguarda R, Robinson RG. Reliability, validity, and clinical correlates of apathy in Parkinson's disease. The Journal of Neuropsychiatry and Clinical Neurosciences 1992; 4(2): 134-9.

62. Marin RS, Biedrzycki RC, Firinciogullari S. Reliability and validity of the Apathy Evaluation Scale. Psychiatry Research 1991; 38(2): 143-62.

63. Cummings JL. The Neuropsychiatric Inventory: assessing psychopathology in dementia patients. Neurology 1997; 48(5 Suppl 6): S10-6.

64. Robert P, Onyike CU, Leentjens AF, et al. Proposed diagnostic criteria for apathy in Alzheimer's disease and other neuropsychiatric disorders. European Psychiatry 2009; 24(2): 98-104.

65. van Dalen JW, Moll van Charante EP, Nederkoorn PJ, van Gool WA, Richard E. Poststroke apathy. Stroke 2013; 44(3): 851-60.

66. Caeiro L, Ferro JM, Costa J. Apathy secondary to stroke: a systematic review and metaanalysis. Cerebrovasc Dis 2013; 35(1): 23-39.

67. Withall A, Brodaty H, Altendorf A, Sachdev PS. A longitudinal study examining the independence of apathy and depression after stroke: the Sydney Stroke Study. International Psychogeriatrics 2011; 23(2): 264-73.

68. Buijck BI, Zuidema SU, Spruit-van Eijk M, Geurts ACH, Koopmans RTCM. Neuropsychiatric symptoms in geriatric patients admitted to skilled nursing facilities in nursing homes for rehabilitation after stroke: a longitudinal multicenter study. International Journal of Geriatric Psychiatry 2012; 27(7): 734-41. 
69. Mayo NE, Fellows LK, Scott SC, Cameron J, Wood-Dauphinee S. A longitudinal view of apathy and its impact after stroke. Stroke 2009; 40(10): 3299-307.

70. Ferro JM, Caeiro L, Santos C. Poststroke emotional and behavior impairment: a narrative review. Cerebrovascular Diseases 2009; 27 Suppl 1: 197-203.

71. Caeiro L, Ferro JM, Figueira ML. Apathy in acute stroke patients. European Journal of Neurology 2012; 19(2): 291-7.

72. Hama S, Yamashita H, Yamawaki S, Kurisu K. Post-stroke depression and apathy: Interactions between functional recovery, lesion location, and emotional response. Psychogeriatrics:The Official Journal of the Japanese Psychogeriatric Society 2011; 11(1): 68-76.

73. Jorge RE, Starkstein SE, Robinson RG. Apathy following stroke. Canadian Journal of Psychiatry - Revue Canadienne de Psychiatrie 2010; 55(6): 350-4.

74. Robinson RG, Jorge RE, Clarence-Smith K, Starkstein S. Double-blind treatment of apathy in patients with poststroke depression using nefiracetam. Journal of Neuropsychiatry \& Clinical Neurosciences 2009; 21(2): 144-51.

75. Krauthammer C, Klerman GL. Secondary mania: manic syndromes associated with antecedent physical illness or drugs. Archives of General Psychiatry 1978; 35(11): 1333-9.

76. Santos CO, Caeiro L, Ferro JM, Figueira ML. Mania and stroke: a systematic review. Cerebrovascular Diseases 2011; 32(1): 11-21.

77. van Almenkerk S, Depla MFIA, Smalbrugge M, Eefsting JA, Hertogh CMPM. Institutionalized stroke patients: status of functioning of an under researched population. Journal of the American Medical Directors Association 2012; 13(7): 634-9.

78. Greenop KR, Almeida OP, Hankey GJ, van Bockxmeer F, Lautenschlager NT. Premorbid personality traits are associated with post-stroke behavioral and psychological 
symptoms: a three-month follow-up study in Perth, Western Australia. International Psychogeriatrics 2009; 21(6): 1063-71.

79. Angelelli P, Paolucci S, Bivona U, et al. Development of neuropsychiatric symptoms in poststroke patients: a cross-sectional study. Acta Psychiatrica Scandinavica 2004; 110(1): $55-63$.

80. Moran P, Stewart R, Brugha T, et al. Personality disorder and cardiovascular disease: results from a national household survey. The Journal of clinical psychiatry 2007; 68(1): 6974.

81. Passier PECA, Visser-Meily JMA, Rinkel GJE, Lindeman E, Post MWM. Life satisfaction and return to work after aneurysmal subarachnoid hemorrhage.[Erratum appears in J Stroke Cerebrovasc Dis. 2011 Sep-Oct;20(5):487]. Journal of Stroke \& Cerebrovascular Diseases 2011; 20(4): 324-9.

82. Pierce LL, Steiner V. What are male caregivers talking about? Topics in Stroke Rehabilitation 2004; 11(2): 77-83.

83. Williams A. What bothers caregivers of stroke victims? Journal of Neuroscience Nursing 1994; 26(3): 155-61.

84. Paradiso S, Ohkubo T, Robinson RG. Vegetative and psychological symptoms associated with depressed mood over the first two years after stroke. International Journal of Psychiatry in Medicine 1997; 27(2): 137-57.

85. Calvert T, Knapp P, House A. Psychological associations with emotionalism after stroke. Journal of Neurology, Neurosurgery \& Psychiatry 1998; 65(6): 928-9.

86. Harris Y, Gorelick PB, Cohen D, Dollear W, Forman H, Freels S. Psychiatric symptoms in dementia associated with stroke: a case-control analysis among predominantly AfricanAmerican patients. Journal of the National Medical Association 1994; 86(9): 697-702. 
87. Aybek S, Carota A, Ghika-Schmid F, et al. Emotional behavior in acute stroke: the Lausanne emotion in stroke study. Cognitive \& Behavioral Neurology 2005; 18(1): 37-44.

88. Skaner Y, Nilsson GH, Sundquist K, Hassler E, Krakau I. Self-rated health, symptoms of depression and general symptoms at 3 and 12 months after a first-ever stroke: a municipalitybased study in Sweden. BMC Family Practice 2007; 8: 61.

89. Hoffmann M, Cases LB. Etiology of frontal network syndromes in isolated subtentorial stroke. Behavioural Neurology 2008; 20(3): 101-5.

90. Carrera E, Bogousslavsky J. The thalamus and behavior: effects of anatomically distinct strokes. Neurology 2006; 66(12): 1817-23.

91. Chan K-L, Campayo A, Moser DJ, Arndt S, Robinson RG. Aggressive behavior in patients with stroke: association with psychopathology and results of antidepressant treatment on aggression. Archives of Physical Medicine \& Rehabilitation 2006; 87(6): 793-8.

92. Starkstein SE, Robinson RG. Mechanism of disinhibition after brain lesions. Journal of Nervous \& Mental Disease 1997; 185(2): 108-14.

93. American Psychiatric Association. Diagnostic and Statistical Manual of Mental Disoders - Text revision. 4 ed. Washington DC: American Psychiatric Association; 2005.

94. Kay SR, Fiszbein A, Opler LA. The Positive and Negative Syndrome Scale (PANSS) for schizophrenia. Schizophrenia Bulletin 1987; 13(2): 261-76.

95. Overall JE, Gorham DR. The Brief Psychiatric Rating Scale. Psychological Reports 1962; 10(3): 799-812.

96. Rabins PV, Starkstein SE, Robinson RG. Risk factors for developing atypical (schizophreniform) psychosis following stroke. The Journal of Neuropsychiatry and Clinical Neurosciences 1991; 3(1): 6-9.

97. Almeida OP, Xiao J. Mortality associated with incident mental health disorders after stroke. Aust N Z J Psych 2007; 41(3): 274-81. 
98. Cals N, Devuyst G, Afsar N, Karapanayiotides T, Bogousslavsky J. Pure superficial posterior cerebral artery territory infarction in The Lausanne Stroke Registry. Journal of Neurology 2002; 249(7): 855-61.

99. Lampl Y, Lorberboym M, Gilad R, Boaz M, Sadeh M. Auditory hallucinations in acute stroke. Behavioural Neurology 2005; 16(4): 211-6.

100. Hausler R, Levine RA. Auditory dysfunction in stroke. Acta Oto-Laryngologica 2000; 120(6): 689-703. 